\title{
pro.posições
}

$e$-ISSN 1980-6248

http://dx.doi.org/10.1590/1980-6248-2017-0120

ARTIGOS

\section{Formação permanente de professores de um município da Grande Vitória/ES: um exercício estético ${ }^{1}$}

\section{In-service teacher training in a city on the urban region of Vitória/ES: an aesthetic exercise}

\author{
Maria Elizabeth Barros (i) \\ Carlos Eduardo Ferraço (ii) \\ Carmen Ines Debenetti (iii)
}

\begin{abstract}
(i) Universidade Federal do Espírito Santo - UFES, Vitória, ES, Brasil. https://orcid.org/0000-00031123-4374, betebarros@uol.com.br.

(ii) Universidade Federal do Espírito Santo - UFES, Vitória, ES, Brasil. https://orcid.org/0000-00024019-591X,ferraco@uol.com.br.

(iii) Universidade Federal do Espírito Santo - UFES, Vitória, ES, Brasil. https:/ /orcid.org/0000-00023872-2311, debenetti.carmen@gmail.com.
\end{abstract}

Resumo:
O artigo trata da experiência de um curso de formação de professores de Ensino
Fundamental da rede municipal de educação da cidade de Serra no estado do
Espirito Santo, Brasil. Visa contribuir com a formulação conceitual e metodológica
no âmbito da formação de educadores no espaço escolar, considerando que os
processos formativos não se reduzem à sua dimensão informacional, mas se
constituem como uma pragmática cognitiva de invenção de si e de mundos que,
igualmente, produz experiências que transpõem os limites das formas subjetivas
instituídas, possibilitando a consolidação de um espaço coletivo de diálogos sobre
o trabalho na escola. A experiência formativa realizada viabilizou, ainda, a criação
de caminhos para pensar a realidade movente, o existir-acontecimento da vida nas
escolas, a partir da perspectiva segundo a qual pensar não é representar um mundo
já dado e, sim, inventar-se a si e inventar mundos. A dialogia dos encontros se
efetivou a partir das experiências advindas do chão da escola por meio das rodas de
conversa. O processo formativo visou a criação de práticas educacionais aliançadas
com o viver na sua dimensão expansiva.
Palavras-chave: formação inventiva, educação permanente, escola

${ }^{1}$ Normalização, preparação e revisão textual: Douglas Mattos (Tikinet) - revisao@tikinet.com.br 


\begin{abstract}
:
The article deals with the experience of a training course for elementary school teachers of the municipal education system in the city of Serra in the state of Espirito Santo / Brazil. It aims to contribute with the conceptual and methodological formulation of educators' training in schools, considering that formative processes are not reduced to its informational dimension. Following this direction of analysis, the training of professionals enabled the consolidation of a collective space for dialogues about work in school. The formative experience carried out also enabled the creation of ways to think of the changing reality, the existence-happening of life in schools, from a perspective, according to which, thinking is not to represent by a previously given world but rather creating oneself and other worlds. The dialogue of meetings took place from the experiences at the school in conversation circles. The formative process aimed to create educational practices grounded on living and its expansive dimension.
\end{abstract}

Keywords: inventive training, permanent education, school

\title{
Introdução
}

A produção subjetiva contemporânea do educador está sujeita a forças poderosas de serialização e de homogeneização, portanto, torna-se importante conceituar a aprendizagem como invenção, recíproca e simultânea, de si e do mundo (Kastrup, 2008). O processo de aprendizagem inventiva tem início no plano das sensações que o território existencial veicula e, em seu decorrer, produz novas formas cognitivas, novos modos de conhecer, de pensar e, então, pode construir outros mundos e outras formas de subjetividade. Assim, um trabalho de formação opera, inicialmente, com o "nível zero da subjetividade" (Schérer citado por Kastrup, 2008, p. 125), que requer trabalhar aquém das subjetividades constituídas. Tal afirmativa implica, portanto, que aprender é, também, produzir formas de subjetividade que indagam os modos naturalizados e inquestionáveis de conhecer-ensinar-aprender.

Entendemos o processo formativo como uma pragmática cognitiva dessa natureza, ou seja, de invenção de si e de mundos que, igualmente, produz experiências que transpõem os limites das formas subjetivas instituídas. Formar implica problematizar o plano do vivido, porta uma potência inventiva e possibilita a produção de diferentes modos de conhecer-ensinar-aprender marcados por experiências nas quais o si e o mundo insurgem dotados de maior consistência. 


\section{pro.posıções}

http://dx.doi.org/10.1590/1980-6248-2017-0120

Seguindo essa linhagem filosófica, o exercício estético-formativo que desenvolvemos abriu-se para o exercício de criação de outras formas de conhecer e praticar as unidades educacionais, por meio de ações que visaram propor-provocar movimentos na contramão do que limita a inventividade do viver, o que foi acontecendo a partir das produções dos educadores em redes de conversação.

Com isso, as produções-experimentações realizadas nos forçaram a pensar as atividades docentes como atos-gestos estéticos, isto é, como configurações da experiência que forçam novos modos de pensar-sentir e produzem novas subjetividades políticas, possibilitando-nos apreender os cotidianos das escolas como espaços-tempos de partilha do sensível em meio às relações estabelecidas entre ética, política e estética (Rancière, 2005).

Entre as ações realizadas com os educadores, destacamos a problematização das narrativas produzidas em termos das relações que eles estabeleciam entre políticas de currículo e cotidianos escolares, levando-os a questionar criticamente as atuais propostas oficiais de currículo, tais como a Base Nacional Comum Curricular. Tivemos como referência a ideia que assume os cotidianos das escolas como espaços-tempos de produção e partilha de políticas de educação, e não apenas como "lugar de aplicação-realização" dos programas oficiais, quando são reduzidos aos modelos de representação das referidas políticas oficiais. Foi com essa perspectiva que a experiência formativa foi se fazendo. A realidade escolar não está dada, ela vai se forjando em meio ao fazer de todos aqueles que militam na escola. Tal atitude filosófico-metodológica adotada se coloca contra os modelos que reduzem o pensamento à representação de um mundo preestabelecido.

Para Tedesco (2012), as práticas de saber, filosóficas ou científicas, quando reduzidas ao modelo da representação, realizam recortes nos processos em movimento, paralisando-os, tomando apenas uma configuração das formas. Nas ciências da vida, passou a vigorar significativa hierarquização que dividiu o conhecimento em confiável de um lado e, do outro, tudo aquilo que fica no terreno pantanoso das fruições e das contemplações cotidianas. Assim, ocorre a separação entre produção científica e produção artística e cotidiana, que cumprem uma função de delimitar fronteiras que segmentam saberes e delimitam poderes. Os questionamentos dessas fronteiras, precisamente, ensinam-nos a trabalhar em educação de outras maneiras, a pensar e a falar de outros modos de educação que não partem de modelos como metro-padrão ou a eles se reduzem. 


\section{pro.posıções}

http://dx.doi.org/10.1590/1980-6248-2017-0120

Em especial, em nossas discussões sobre os currículos e suas relações com os cotidianos escolares, foi interessante perceber os questionamentos e os deslocamentos nas narrativas dos educadores envolvidos nos processos de formação. De uma perspectiva inicial de currículo reduzido ao texto escrito e aos documentos governamentais, eles passaram a considerar suas atividades docentes cotidianas como expressões de políticas de currículo, como ações que problematizam as formas e as segmentações hierarquizadas que, reiteradamente, são produzidas e reforçadas nas escolas.

Como professora de uma turma do $1^{\circ}$ ano do Ensino Fundamental, o que mais ouvi dizer foi: "criança do $1^{\circ}$ ano não escreve", "criança pequena não tem o que dizer", "se as crianças do $1^{\circ}$ ano forem para o $2^{\circ}$ ano reconhecendo as letras e formando sílabas, está ótimo" etc. Essas frases, que remetem a uma infância "sem voz" ou a uma criança como "tábula rasa", provocam meu pensamento em relação à necessidade de experiências nos espaços-tempos escolares que possibilitassem uma escrita autoral. Nesse sentido, os processos de aprender-ensinar produzidos com aquelas crianças eram tentativas de fugir dos enquadramentos da imagem que já era determinada a priori a elas, a de "não escritor" (Rosany², comunicação pessoal, 2015).

Autores como Benjamin (1996), Bergson (2006) e Deleuze (2006) nos fazem pensar e problematizar as segmentações hierarquizadas que se instauram na educação, à medida que entendemos que os campos da arte, da ciência e da filosofia se intercambiam e se entrecruzam incessantemente. Em um movimento contrário a essa hierarquização entre disciplinas e faixas etárias, interpõe-se uma linha transversal (Tedesco, 2012) que, ao romper com as formas de organização conhecidas, propõe outros modos de funcionamento, nos quais se fala de componentes de intercessão, de elementos heterogêneos sem submetê-los à homogeneização, como pudemos observar na narrativa apresentada pela professora.

Nos processos de formação em pauta, buscamos acessar, então, a dimensão estético-processual da experiência, como possibilidade de coengendrar novos modos de viver, pensar e trabalhar, em nosso caso, na educação. Com isso, para melhor acompanhar os processos de subjetivação em curso nas atividades da área da Educação, vislumbramos acolher o feixe de forças que explicitasse o caráter estético que alimenta o que está sempre se fazendo, o que exige a desconstrução de formas desgastadas de viver-ensinar-aprender que já não dão conta da dimensão da criação estética das situações vividas. O estranhamento dos modos habituais de trabalhar em educação interroga tais formas vigentes, desestabilizando-as e exigindo

2 Professora alfabetizadora. 


\section{pro.posições}

http://dx.doi.org/10.1590/1980-6248-2017-0120

outras composições mais condizentes com as resoluções solicitadas no concreto dos cotidianos escolares.

Foi nesse sentido que demos ênfase, no processo formativo com trabalhadores de Educação de Serra/ES, a uma formação que não fosse destituída de sua relação ético-estética e de sua potência de interferir nos acontecimentos cotidianos. Um exercício inventivo de dar a conhecer o próprio mundo, de forma a não se tornar parte de uma discursividade redundante e massificada, de maneira a não ratificar seus efeitos sobre a vida, resultando numa paralisação do pensamento em formas acabadas e regidas pela repetição sem diferença.

O aporte adotado, então, foi o de acreditar que a formação de educadores se faz como experiência. Tal exercício é um ato de linguagem e, como tal, possui uma dimensão performática de produção e transformação de realidades. Devido a esse caráter pragmático, o exercício seguiu em direção à ativação dos planos genéticos de modos inventivos de trabalhar, movimentos que o fazem potente para desviar-se de uma simples junção de informações que obstrua os fluxos sensíveis da experiência, reduzindo suas múltiplas direções possíveis na busca de resoluções, como podemos ver na narrativa que se segue:

Todos os anos, desde que entrei no Ensino Fundamental em 2014, é na reunião de início de ano que se define qual grupo de professores ficará responsável por produzir os murais da entrada da escola, de acordo com as datas comemorativas selecionadas, tais como: carnaval, páscoa, festa junina etc. Assim como eu, havia mais duas professoras novatas na escola em 2014, e acabamos "sobrando" e nos juntamos, pois os grupos foram rapidamente formados por quem já se conhecia, além de escolherem as datas entendidas como as "mais fáceis" de serem transformadas em murais, utilizando, inclusive, materiais do ano anterior, conforme relatos. O mural do carnaval foi um dos mais disputados, porque era só colocar umas máscaras e serpentinas. O grupo que escolheu a Páscoa pensou em colocar carneirinhos (para lembrar o Cordeiro de Deus) produzidos pelos alunos. E para nós ficou o Dia da Consciência Negra. Para não ficar apenas um painel feito por professoras, sem a participação dos alunos, sem estar relacionado à produção de conhecimentos e meramente decorativo, planejamos fazer pesquisas e atividades sobre a história e a cultura do povo brasileiro, tentando fazer com que as crianças se percebessem e se valorizassem independentemente da cor da pele, entre outros aspectos. Os trabalhos acabaram por seguir um caminho de valorização das identidades e não exclusivamente sobre a "Consciência Negra" (Evelize³, comunicação pessoal, 2015).

${ }^{3}$ Professora do $2^{\circ}$ ano. 


\section{pro.posıções}

http://dx.doi.org/10.1590/1980-6248-2017-0120

$e$-ISSN 1980-6248

\section{Uma experiência de formação como exercício estético: questões (im)pertinentes no âmbito educacional}

Em nossas discussões durante o processo de formação, não interessava que tal processo desse passagem a um saber preestabelecido e, sim, que promovesse a abertura à potência de criação. Trata-se de olhar para além de um eu, aquilo que se encontra ainda em estado nascente que, por sua natureza "incriada", ainda se mistura ao plano do silêncio (Fonseca, 2007).

Com essa direção de análise, os objetivos do processo formativo foram: (i) provocar movimentos de abertura nos campos da formação e das práticas de ensino para outras forças não instituídas de produção de subjetividade/conhecimento; (ii) potencializar os trabalhadores em educação para intervir na problemática de produção de subjetividade e de conhecimento, exercitando o pensamento e assumindo sua condição de também produtores de políticas de educação; (iii) afirmar a formação como atividade ético-estética do pensamento criando outros modos de ser educador e de ser aluno, produzindo um pensamento crítico; (iv) contribuir para a ampliação do poder de agir dos trabalhadores em Educação; (v) disseminar e iniciar práticas de escrita no cotidiano escolar, tendo em vista a afirmação das tramas vividas que compõem esse território.

Tais objetivos se concretizaram em um curso que se dividiu em três módulos: as questões do cotidiano na escola, os processos de trabalho na escola e a aprendizagem inventiva. A metodologia utilizada foi a da alternância, ou seja, parte da carga horária se efetivava com aulas presenciais e outra parte com atividades de dispersão, que eram construídas coletivamente nas aulas presenciais. Os cursistas deveriam, a partir das temáticas discutidas no coletivo, produzir intervenções e análises do seu cotidiano de trabalho nas escolas. Tais experimentações eram apresentadas e debatidas nos grupos nas aulas presenciais.

O processo formativo efetivado com os educadores do município de Serra possibilitou uma experimentação que priorizou um trabalho em grupo, que consolidasse um espaço coletivo de pensamento na escola. Partimos do entendimento de que a formação de um profissional da educação não termina com a obtenção de um diploma acadêmico, mas trata-se de um processo permanente e efetiva-se no curso da atividade laboral.

Nesse sentido, operamos com teorias que colocam como prioridade a problematização do mundo com seus acontecimentos singulares e imprevisíveis para pensar o ser vivo concreto 


\section{pro.posições}

http://dx.doi.org/10.1590/1980-6248-2017-0120

que age em determinado lugar espaço-temporal-histórico. Não priorizamos um pensamento representacional que colocaria os educadores como reprodutores do que está definido nas políticas prescritivas oficiais. A intenção foi de instigar os educadores em processo de formação a se deslocar dos lugares habituais em que trabalhavam, de modo a vivenciar diferentes processos de aprendizagem inventiva, que só se efetivam por meio da problematização das realidades constituídas.

Trabalhamos, então, com problematizações em que se inventam caminhos para pensar a realidade movente e o existir-acontecimento da vida no contexto da formação de educadores, exercício que se dá na inversão do sentido habitual do pensamento, criando espaços-tempos outros nas escolas. Assim, novos sentidos puderam ser produzidos na reflexão e na multiplicidade de vozes dos encontros presenciais, em que cada participante oferecia uma visão singularizante para efetuar a potência do coletivo.

Ao ser solicitado para desenvolver uma atividade em comemoração do Dia da Mulher na Educação de Jovens e Adultos, um professor de História apresentou para cada turma a proposta de homenagear três mulheres da comunidade escolar. Entre as escolhidas, estavam a estudante mais idosa, uma auxiliar de serviços gerais, e uma professora que se destacava pelos trabalhos realizados na escola. Um momento simples em sua organização, mas que fomentou sentimentos de orgulho por todos da comunidade escolar. A nosso ver, essa ação pontual transformou o significado do Dia da Mulher até então comemorado na escola, ao buscar valorizar não mulheres da mídia, como Madre Teresa ou Michele Obama, mas pessoas da própria comunidade, indicadas pelo coletivo de alunos e educadores, rompendo com a construção social preguiçosa do clichê de recortar fotos e admirar ídolos distantes. Ainda que com diversos contratempos, o espaço escolar é um turbilhão criativo (Leidiane ${ }^{4}$, comunicação pessoal, 2015).

Tal experimentação na formação de educadores abre outras formas de conhecer e praticar o contemporâneo, inventando-o. Possibilita preservar nossa capacidade de imaginar em ausência de um referente, pois as imagens que escapam das representações já prontas que encontramos no mundo se constituem como criação. Imagens que não são efetivamente cópias da realidade, mas potência que movimenta modos de pensar na escola como atividade criadora.

As situações vividas se constituíram como oportunidades para que os educadores experimentassem um processo formativo em sua potência genética, no sentido de desafiar o pensamento a superar a representação clichê, pensar e aprender de forma inventiva e, assim, possibilitar aos alunos o trabalho com o pensamento. Dessa forma, uma pedagogia da imaginação pode ser inventada a cada instante, uma pedagogia que faça mover o pensamento

\footnotetext{
${ }^{4}$ Pedagoga.
} 


\section{pro.posıções}

por outras imagens com o objetivo de criar com educadores e alunos protagonistas que transformam sua atividade, num processo incessante de busca por expansão de seu poder de agir.

Nesse sentido, acreditamos que uma formação, em sua dimensão de experimentação, pode ser tomada como referência para uma política educacional capaz de transformar obstáculos em invenção de si e de mundos; portanto, uma política de aprendizagem inventiva.

Tudo começou quando resolvemos comprar uma mesa de totó. Colocamos o brinquedo para ser usado durante os recreios e momentos livres. No decorrer do tempo fomos notando que só os meninos brincavam e as meninas ficavam observando. Resolvemos, então, conversar com as meninas para tentar descobrir o motivo de não brincarem e as respostas foram as mesmas: os meninos diziam para elas que futebol é coisa de menino, que elas não entendiam nada de totó e que fossem pular corda. Conversamos com os meninos, tentando mostrar que totó ou futebol não é coisa só de menino, e dei diversos exemplos de mulheres que jogam futebol, mostrando que eles deveriam incluir as meninas na brincadeira, não como um favor, mas respeitando os direitos delas. Depois de muita conversa, decidimos que o totó seria um dia para cada grupo e funcionou assim por quatro semanas. Com o passar do tempo, fomos percebendo que as meninas realmente não sabiam jogar e os próprios meninos foram ensinando. Hoje não existe mais o dia dos meninos e o dia das meninas. Todos os alunos, indiscriminadamente, conseguem jogar totó de forma democrática e respeitosa. Com isso, percebemos que, furando o clichê "futebol não é coisa para mulher", conseguimos, de modo coletivo, que todos participassem da brincadeira (Manoel ${ }^{5}$, comunicação pessoal, 2015).

Os processos de formação de trabalhadores da educação realizados nos levaram à problematização da forma como o conceito de formação tem sido dimensionado. O processo se desenvolveu visando pensar a formação de vida-trabalho no campo da educação, de maneira a interferir nos modos como os processos formativos se efetivam nesse campo. Como já indicado, optamos por uma diretriz na qual a formação de educadores, visando problematizar as atividades desses trabalhadores, se efetivou a partir de aulas realizadas com rodas de conversa, quando os participantes eram estimulados a confrontar suas experiências no campo da Educação e analisar os efeitos dessas práticas que vislumbram uma educação de qualidade técnico-social. Para tanto, tomamos a atividade de apoio como estratégia dos processos formativos. Tal atividade, que vamos nomear "formação-apoio", foi assumida como intercessora em um fluxo coletivo de análise dos processos de trabalho e reorganização dos estabelecimentos de ensino.

\footnotetext{
${ }^{5}$ Professor de Educação Física.
} 


\section{pro.posıções}

$e$-ISSN 1980-6248

http://dx.doi.org/10.1590/1980-6248-2017-0120

Em uma organização do trabalho pedagógico baseada em formas de gestão verticalizadas e segmentadas, experiência hegemônica nos espaços-tempos educativos, a proposta de fazer coletivamente exige esforço e pode gerar a sensação de árdua luta e realizarse quase como ato heroico e personalizado. Nessa atitude, as responsabilidades podem restar individualizadas e os esforços produzirem, por vezes, práticas de exclusão em relação aos outros educadores que, a princípio, parecem representar o comodismo, a despotencialização e a resistência ante a mudança. As culpabilizações, reclamações e desqualificações dos eventos ocorridos nos estabelecimentos educacionais dominam, muitas vezes, o tom das rodas de conversas de modo a produzir, em muitos casos, práticas individualizadas.

Normalmente recai sobre os ombros do professor o resultado ruim da educação. Porém, se olharmos o todo, veremos que existem diversos fatores que envolvem as vivências e as práticas educacionais, desde o sistema, a qualidade da formação do profissional, o ambiente escolar, a comunidade onde a escola está inserida, as famílias dos alunos, os grupos de trabalho das mais diversas áreas no contexto da escola, da administração e da gestão da educação. Falando especificamente do Centro Municipal de Educação Infantil onde atuo, tudo parece muito rotineiro, tradicional no que se refere à gestão e à administração da escola, com um grupo de docentes em fase de aposentadoria, fechados a algumas interferências, detentores de um saber adquirido com a prática e sem motivação para o novo e, quiçá, para o rotineiro. No entanto, no meio de toda essa imobilidade, vislumbra-se uma figura diferenciada, com talento musical, artístico que encaminha seu trabalho de forma autônoma, criativa, conseguindo ganhar com facilidade o interesse dos alunos. No entanto, apesar de toda a criação metodológica que desenvolve, mostra-se fechada ao diálogo em termos do seu trabalho, afirmando não se sentir à vontade em partilhar com os colegas suas práticas e materiais. Apesar de ser sempre alvo de reconhecimento, não chega a produzir um movimento de mobilização do coletivo, ficando restrita ao seu próprio desempenho (Neila ${ }^{6}$, comunicação pessoal, 2015).

É importante visibilizar que as dificuldades relativas aos processos de mudança não são exatamente pessoais, ainda que vividas de forma individualizada. A descrença, o descrédito, o comodismo não são defeitos dos sujeitos, mas efeitos dos modos de vida e do trabalho educacional que se deseja mudar. Seguindo essa direção, destacamos a importância da escuta e da roda de conversa no processo formativo para fazer circular também essas dificuldades, palco do trabalho desafiador de todos sobre todos que estão em atividade no campo da Educação.

Interessou-nos, ainda, problematizar práticas formativas reduzidas a processos informacionais e apontar a importância do debate, da problematização e do diálogo, dos tensionamentos que fazem o trabalho pedagógico avançar, indagando sempre o modo como o processo de ensino-aprendizagem se realiza a partir de seus efeitos, e não de suas idealizações

${ }^{6}$ Pedagoga. 


\section{pro.posıções}

http://dx.doi.org/10.1590/1980-6248-2017-0120

prescritivas. Não vislumbramos procurar os culpados ou os responsáveis, nem invisibilizar ou ignorar as narrativas que reforçavam os próprios clichês que, supostamente, desejavam combater, como nos pareceu na narrativa a seguir:

Tudo em nossa vida tem início dentro de um contexto familiar. O casal, quando está namorando, projeta uma união com direcionamento de se unir em matrimônio, ter uma família perfeita. Por este motivo, entende "família" como a comunidade doméstica que, em torno do amor conjugal, se desenvolve e cresce. Infelizmente, hoje em dia se diz muito sobre "os novos tipos de família". Grandes projetos de lei são elaborados para contrapor a natureza da família. Casais homossexuais reivindicam o termo "família" para suas uniões. Legisladores de diversos países entram na briga e tomam as rédeas das defesas dessas causas. A sociedade vai se embrenhando por um caminho mais difícil onde os referenciais são perdidos e facilitando, assim, certas aceitações, mas, afinal de contas, onde está aquela ideia em que o casal projeta ter uma família perfeita? Aí vem a quebra do clichê. Tipos de família diferentes que muitas vezes se diz que são aceitáveis, mas, na verdade, a sociedade tem outros olhares sobre eles, levando-os a serem vistos como diferentes e discriminando-os (Márcia Regina7 ${ }^{7}$, comunicação pessoal, 2015).

De fato, durante a formação, buscamos criar movimentos de tensão e de conversas, com o intuito de confrontar modos diversificados de funcionamento dos processos educacionais. Estes não são outros que o fortalecimento do coletivo no aumento dos graus de análise e ação.

\section{Dimensões do processo formativo: a função apoio}

Seguindo essa direção da análise, o processo formativo que experimentamos com os educadores se fez como apoio, formação-apoio, ou seja, oferecendo suporte para que os próprios trabalhadores pudessem colocar em análise suas práticas e produzir outras. Assim, operamos com um formar como modos de produzir apoio, sustentando análises. Com esse objetivo, consideramos quatro dimensões dessa função apoio do processo formativo, pautadas na pesquisa de Barros, Cesar, Gomes \& Daros (2014).

A primeira dimensão é a interventiva. Fazer formação-apoio é intervir nos processos de trabalho, estratégia de intervenção nos modos de educar e gerir atualizados pelos trabalhadores em Educação. Mas como fazê-lo? De que modo intervir nos processos de trabalho? Salvaguardadas as devidas singularidades das diversas experiências, podemos destacar uma diretriz comum nesse sentido: a intervenção nos processos de trabalho se dá por meio de sua análise coletiva, que se produz em espaços e arranjos distintos, como rodas de conversa, grupos

\footnotetext{
${ }^{7}$ Pedagoga.
} 


\section{pro.posıções}

http://dx.doi.org/10.1590/1980-6248-2017-0120

de trabalho, de estudo, conselhos, cursos formativos, fóruns etc. Tais arranjos vinculam-se a uma experiência recorrentemente remetida ao fazer roda, como método de circulação de saberes e afetos, de produção de relações lateralizadas, que potencializam a produção coletiva e a cogestão.

No caso da formação dos educadores do município de Serra, a dimensão interventiva se efetivou por meio da criação de dispositivos como as rodas de conversa e o debate sobre situações vividas nas escolas. Tais dispositivos viabilizaram a troca de experiência e o diálogo entre os educadores. Em várias ocasiões afirmavam:

Na escola não temos tempo a oportunidade de conversar. É tudo muito corrido. Agora estamos vendo a importância de ouvirmos os colegas. Essa parada da rotina nos faz pensar e, assim, podemos inventar outras maneiras de trabalhar. Estamos analisando o nosso trabalho para poder fazer diferente, de forma menos sofrida e mais criativa (Rita ${ }^{8}$, comunicação pessoal, 2015).

O formador-apoiador, antes que "redentor", também sofre o processo de intervenção. Para isso, aliança-se com situações e acontecimentos catalisadores de forças, que intensificam a análise nas relações nos grupos e entre eles, nos processos de trabalho, potencializando a produção coletiva. A atividade do formador-apoiador, portanto, está na criação e na aposta em condições que desacomodem instituições que se atualizam nos estabelecimentos, nos grupos, principalmente no que se refere às relações de saber-poder.

A segunda dimensão é a cogestionária: a dimensão interventiva nos abre à cogestionária, uma vez que se busca o fortalecimento de uma dimensão cogestiva, fundada em relações de interdependência que produzem o trabalhar. Tal dimensão não se afirma como um fim ou uma meta a ser alcançada num depois, mas refere-se ao próprio caminho, por isso as estratégias são aquelas que se vinculam a uma análise coletiva do que acontece e do que pode devir entre todos.

A atividade de formação-apoio, nessa esteira, se coloca como experiência inventiva, pois está constantemente a transformar-se naquilo que ganha contorno a partir do trabalho feito com os outros. O formador-apoiador está sempre pendente na concorrência entre direções não necessariamente harmônicas, que lhe exigem tomar determinadas direções e assumir certos riscos no processo de intervenção.

\footnotetext{
${ }^{8}$ Professora de uma escola municipal de Ensino Fundamental.
} 


\section{pro.posıções}

http://dx.doi.org/10.1590/1980-6248-2017-0120

A terceira é a dimensão formativa. Tal dimensão do apoio é inseparável da intervenção. Baseia-se no exercício da produção de espaços coletivos que fomentem a emergência, produção e compartilhamento de saberes coletivos e situados, dando visibilidade e potencializando a criação de outros-novos modos de trabalhar e cuidar, minando as hierarquias que distinguem os que sabem dos que não sabem, bem como a desqualificação de alguns saberes em detrimento de outros.

Assim procedemos. Foi possível o exercício de uma formação que tivesse, na potência disruptiva dos saberes e fazeres compartilhados, seu grau de pertinência e índice de eficiência. A formação que promovemos fundamentou-se em uma noção de aprendizagem que não se baseia na mera reprodução e aplicação dos conteúdos e técnicas transmitidos, mas na ideia de que aprender é operar sobre determinadas práticas de modos diferentes dos que se estava acostumado, transformando as formas de ser, de se relacionar e de produzir mundos.

As informações são fagocitadas, ingeridas, transformadas, produzindo-se outras subjetividades, outras formas de estar no mundo. Tocamos nesse ponto em que a formação se desprende de seus modelos tradicionais escolarizados e pode se afirmar como processo, uma dimensão formativa imiscuída no cotidiano, extremamente aliançada ao desdobramento da atividade de trabalho, em que os sujeitos constroem a si e ao mundo.

Novos desafios se impõem ao exercício da formação-apoio como atividade de trabalho: quais estratégias construir? Como superar a descrença em propostas que visam transformar o trabalho em educação e ampliar a democracia institucional? Como combater o sentimento de isolamento em que não se percebe no outro um aliado para a resolução das questões que nos afligem no trabalho nas escolas? Como já afirmamos, o trabalho sempre se dá num plano coletivo. Não se trabalha sozinho. No trabalho em Educação, esse entendimento é radicalizado, pois supõe o exercício da alteridade, da inclusão do outro e suas demandas singularizantes. Nesse sentido, durante os processos formativos, os educadores puderam perceber a força dos coletivos de trabalho na transformação das situações desagradáveis e desfavoráveis vividas nas escolas: "Não é fácil fazer isso, mas fica cada vez mais claro que não mudamos nada sozinhos, isolados. As coisas só mudam quando nos juntamos e fazemos juntos. Esse negócio de herói, só nos contos de fada" (Sandra ${ }^{9}$, comunicação pessoal, 2015).

\footnotetext{
${ }^{9}$ Professora de um centro municipal de Educação Infantil.
} 


\section{pro.posıções}

http://dx.doi.org/10.1590/1980-6248-2017-0120

$e$-ISSN 1980-6248

A quarta dimensão é a clínica, entendida como experiência de desvio, que produz bifurcações no percurso de vida, criando novos territórios existenciais, como produção de diferenciação, de desestabilização. Essa postura adotada indica um exercício de escuta, de fazer o outro [com o outro] analisar, pensar, que objetiva a abertura a novos possíveis, e não o fechamento a categorias predefinidas, baseadas em uma noção adaptacionista, utilitária ou ortopédica. Assim intervimos. Assim atuamos. Uma clínica da ação, e não do enquadramento. Optamos por abordar a dimensão clínica da formação-apoio por um viés específico, dentre os inúmeros possíveis, que é o de uma clínica do trabalho em Educação. É preciso, então, cuidar da escola, do espaço-tempo de produção de educação em que se desenvolve o trabalho. Em última instância, é preciso cuidar do próprio trabalho, para evidenciar que os diferentes atores que compõem os estabelecimentos educacionais são seres capazes de transformar o que fazem.

Cuidar do trabalho, neste caso cuidar das práticas em Educação, é produzir condições para que nas escolas as relações estejam pautadas nas singularidades das situações e dos processos de subjetivação e de sujeitos, a partir de suas demandas. É lutar contra as práticas de formatação de sujeitos ou ações. É disponibilizar-se à inventividade, potencializar a gestão dos imprevistos e dos inantecipáveis, coletivizar riscos, suportar os insucessos e compartilhar os avanços.

\section{Considerações finais}

Ao longo do artigo, buscamos afirmar um processo formativo em que os educadores discutem com seus pares a atividade de trabalho e, sobretudo, as ações que buscam evitar um processo de descrença na possibilidade de mudança no que está instituído nas escolas. Os trabalhadores perceberam a importância de momentos como esses, de pausas para pôr a atividade em análise, cuja produção de sentido induziu o interesse por encontros coletivos nas escolas para discutir o trabalho, trocar experiências e criar ações aliançadas com a potência criativa dos humanos. Fazer pausa é quebrar os automatismos que tendem a isolar o trabalho de suas dimensões aquém e além da prescrição. Os encontros coletivos de análise da atividade escolar podem permitir o acesso a um processo de produção de si e do mundo do trabalho na contramão de uma ordem burocrática que pode amordaçar os processos criadores nas escolas. 


\section{pro.posıções}

http://dx.doi.org/10.1590/1980-6248-2017-0120

O trabalho de formação-apoio efetivado reafirma uma aposta metodológica que considera que a atividade do sujeito se dirige para a atividade dos outros e para suas outras atividades. Esse caminho - o método - reafirma que a atividade do sujeito não se volta unicamente para o objeto da tarefa. Clot (2006) nos diz que, quando uma atividade de trabalho é privada de um destinatário, ela perde o seu sentido, o que implica afirmar que o destinatário também atribui sentido ao trabalho. A atividade de trabalho atravessa o agente trabalhador, não sendo determinada apenas por ele, uma vez que a atividade de trabalho se dá na relação por ela instaurada.

A atividade pedagógica é, assim, efeito de um plano relacional cujos responsáveis são ambos educadores e alunos. Essa corresponsabilidade dá primado à relação, não havendo privilégio de um dos seus polos. Fazendo uma inflexão na afirmação de Clot (2006), diríamos que, ao se lançar luz às relações que se efetivam nos processos de trabalho em Educação, entramos em contato com o plano de produção da experiência do trabalho educacional por definição aquém e além dos indivíduos. É nesse sentido que se pode dizer que o trabalho é atividade, produção, relação entre os humanos.

Por conseguinte, reafirmamos que, durante o processo formativo, a atividade de trabalho não partiu de metodologias que privilegiam os princípios da representação de realidades tidas como dadas, uma vez que o cotidiano laboral nos estabelecimentos educacionais se apresenta como uma complexa rede que se tece no curso da atividade. Assim, essa direção de análise dos mundos do trabalho no campo da Educação vai na contramão de uma postura segundo a qual conhecemos a realidade para fazer previsões que viabilizariam o agir, o que se expressa no paradigma segundo o qual conhecemos para, então, transformar a realidade. Tal metodologia, pautada num pensamento representacional, mostra-se ineficaz para acessar a experiência laboral, que só se faz acompanhando o curso da atividade em situação de trabalho vivo em ato. A dimensão movente, em constante processo de movimento, do trabalho humano, exige metodologias de análise do trabalho que possam acompanhar tal movimento.

Então, ao percorrer os atalhos construídos pelos trabalhadores, inquirimos: como o trabalho se efetiva como uma forma de criação? Como, ao trabalhar, o educador inventa outros modos de existência? Como, ao trabalhar, o educador aumenta seu poder de agir? É preciso criar a si e criar o trabalho, gerir modos de operar num jogo constante de análise dessas composições. 


\section{pro.posições}

http://dx.doi.org/10.1590/1980-6248-2017-0120

Trata-se de uma insistência, uma teimosia em tomar o trabalho como necessariamente da ordem do vivo, nesse entremeio de criação, afirmando o trabalho educacional a partir de um construtivismo radical. Esse modo de fazer educação nos faz artesãos, fabricando passos, regras, hierarquias, apostando na ordenação de passado, de presente, de futuro. Como acompanhar o plano da experiência do labor em Educação? Como dar expressão a essa experiência do labor, entendendo que dar expressão é o próprio conhecimento? Não existem respostas prontas para tais questões, nem as desejamos. Foi no exercício da atividade de trabalho que as indagações foram encaminhadas e as respostas forjadas.

Quando um trabalhador da educação está em situação não prevista e é preciso inventar uma solução, essa invenção corresponde ao estilo que se torna, "por sua vez, a transformação por um sujeito, em recursos para agir em suas atividades reais" (Clot, 2006, p. 50). Essa invenção se produz na experiência concreta, ou seja, em situação de trabalho, e se efetiva com base em um patrimônio.

A aposta de Clot (2006) na estilização operada pelo trabalhador como invenção encarnada em experiência concreta do trabalho indica esse plano de criação característico da experiência do labor. Vai-se da dimensão comum coletiva à dimensão singularizadora de um estilo produzido pelos educadores. Tal plano de criação do trabalho educacional gera um duplo efeito, de objetivação (o trabalho como atividade específica) e de subjetivação (o trabalho como estilo de um trabalhador-educador).

Essa estilização se expressa nas narrativas de alguns educadores que participaram do processo formativo no município de Serra. Tais narrativas (aqui selecionamos apenas duas delas) são materiais ricos que afirmam essa diretriz ético-política indicada no nosso trabalho: a atividade no campo da Educação não se faz apenas por prescrições, mas, principalmente, por um processo estético-formativo:

Pendurei um retroprojetor na viga da escola para projetar uma obra da Tarsila do Amaral. Projetei a imagem no chão e trouxe o Grupo 3 para que os alunos comtemplassem a cena. Espalhei trigo no chão para que fizessem outras imagens e eles gostaram muito. Depois trouxe o Grupo 6 e coloquei papel no chão onde a cena estava projetada, e os alunos usaram canetinhas, lápis de cor, giz de cera e fizeram a releitura do quadro de uma forma diferente e dinâmica. Assim, vou criando situações outras para os processos de aprendizagem, tentando fugir dos clichês (Sonia ${ }^{10}$, comunicação pessoal, 2015).

${ }^{10}$ Professora de Artes de um centro municipal de Educação Infantil. 
Numa discussão acerca das falas que um determinado aluno apresenta extrapolando o limite, ao tomar as devidas providências, a família é convocada várias vezes, quando finalmente comparece a mãe e justifica, para a unidade de ensino, a necessidade de trabalhar, por isso sai todos os dias às cinco horas da manhã, prepara o café do filho, atentando, antes de sair, se o celular dele está com o horário correto para despertar, pois, como a mãe nos coloca, é arrimo de família e necessita trabalhar para pagar as contas e colocar comida na mesa. Essa situação nos indica que a unidade de ensino, o sistema, enfatiza que é de responsabilidade da família o acompanhamento escolar conforme preconizado no Estatuto da Criança e do Adolescente. Com as nossas conversas, foi possível perceber que trabalhamos com uma concepção abstrata do que é acompanhamento. A partir da análise dessa situação, uma avalanche de outras pôde ser reconsiderada (Paula11, comunicação pessoal, 2015).

\section{Referências}

Barros, M. E. B., Cesar, J., Gomes, R., \& Daros, R. (2014). Verbos do apoio institucional em pesquisa: transversalizar, transdisciplinarizar e fortalecer redes de trabalho-vida na saúde. In R. Pinheiro, F. H. Silva, T. C. Lopes, \& A. G. Silva Jr. (Orgs.), Práticas de apoio e a integralidade no SUS: por uma estratégia de rede multicêntrica de pesquisa (pp. 83-110). Rio de Janeiro: Cepesc.

Benjamin, W. (1996). Magia e técnica, arte e politica: ensaios sobre literatura e bistória da cultura (Obras Escolhidas, Vol. 1, 7a ed.). São Paulo: Brasiliense.

Bergson, H. (2006). O pensamento e o movente. São Paulo: Martins Fontes.

Clot, Y. (2006). A função psicológica do trabalho. Petrópolis: Vozes.

Deleuze, G. (2006). A ilha deserta. São Paulo: Iluminuras Ltda..

Fonseca, T. M. G. (2007). Modos de pesquisar, modos de subjetivar. In T. M. G. Fonseca, S. Engelman, \& C. M. Perrone, Rizomas da reforma psiquiátrica (pp. 19-28). Porto Alegre: Sulina.

Kastrup, V. (2008). Cartografias literárias. In V. Kastrup, S. Tedesco, \& E. Passos, Políticas da cognição (pp. 113-135). Porto Alegre: Sulina.

Rancière, J. (2005). A partilha do sensivel: estética e política. São Paulo: Editora 34.

11 Professora de uma escola municipal de Ensino Fundamental. 
Tedesco, S. H. (2012). Pensando a ética da clínica das drogas: linguagem, subjetivação e a experiência das drogas. Tese de Concurso para Professor Titular, Universidade Federal Fluminense, Rio de Janeiro.

Submetido à avaliação em 13 de julho de 2017; revisado em 14 de junbo de 2019; aceito para publicação em 17 de junbo de 2019. 